\title{
ROLLAND Denis. 2000. La Crise du modèle français. Marianne et l'Amérique latine. Culture, politique et identité. Rennes : Presses Universitaires de Bretagne.
}

Gérard Vigner

\section{OpenEdition}

\section{Journals}

Édition électronique

URL : https://journals.openedition.org/dhfles/2336

DOI : $10.4000 /$ dhfles.2336

ISSN : 2221-4038

Éditeur

Société Internationale pour l'Histoire du Français Langue Étrangère ou Seconde

Édition imprimée

Date de publication : 1 décembre 2002

Pagination : 192-194

ISSN : 0992-7654

Référence électronique

Gérard Vigner, «ROLLAND Denis. 2000. La Crise du modèle français. Marianne et l'Amérique latine. Culture, politique et identité. Rennes : Presses Universitaires de Bretagne. », Documents pour l'histoire du français langue étrangère ou seconde [En ligne], 29 | 2002, mis en ligne le 15 mai 2014, consulté le 27 mai 2021. URL : http://journals.openedition.org/dhfles/2336 ; DOI : https://doi.org/10.4000/dhfles. 2336

Ce document a été généré automatiquement le 27 mai 2021.

(C) SIHFLES 


\title{
ROLLAND Denis. 2000. La Crise du modèle français. Marianne et l'Amérique latine. Culture, politique et identité. Rennes : Presses Universitaires de Bretagne.
}

\author{
Gérard Vigner
}

$1 \quad$ Il n'est jamais inutile de revisiter les mythes. Les représentations qu'ils suscitent ont souvent pour effet de masquer la réalité des faits historiques et de donner du présent, par voie de conséquence, une image qui fausse la perception que l'on peut s'en donner. Le rayonnement politique et culturel français en Amérique latine dans la première moitié du $\mathrm{XX}^{\mathrm{e}}$ siècle fait partie de ces mythes dans la mesure où il mêle de très nombreuses images, celles des intellectuels latino-américains séjournant à Paris, grands connaisseurs de la culture française, d'Alejo Carpentier à Pablo Neruda, celle de l'Aéropostale avec les figures d'Antoine de Saint-Exupéry ou de Jean Mermoz ou encore celle des chercheurs et universitaires français qui participèrent à la fondation de l'Université de Sao Paulo. Images de relations intenses, riches d'échanges nombreux entre artistes, intellectuels, hommes politiques, ambassadeurs, en regard desquelles la situation présente ne peut que paraître terne et de moindre intérêt. Le projet de Denis Rolland n'est pas de nier cette crise, puisqu'elle constitue la matière de l'ouvrage, mais de ne pas s'enfermer dans une vision purement doloriste des faits et de la traiter en historien. Comme il le rappelle en conclusion: "l'historien a mieux à faire que de travestir d'oripeaux fournis par un travail ponctuel ce discours classique sur la décadence. En cherchant une réalité, des représentations collectives propres à deux sociétés qui se regardent, il espère faire œuvre moins inutile qu'en proclamant une prétendue vérité » (p. 379).

2 L'ouvrage couvre, en gros, la période qui va du début du $\mathrm{XX}^{\mathrm{e}}$ siècle aux lendemains de la Libération et examine de façon très attentive comment à partir d'une situation 
caractérisée au début du siècle par le voisinage des élites et un "gallicisme mental » très marqué, se met en place une logique d'éloignement que les deux guerres ne feront qu'accentuer. L'intérêt de cet ouvrage réside dans un examen attentif des mécanismes à l'œuvre et que l'on ne saurait attribuer, selon Denis Rolland, au seul effet de la médiocre ambition des partenaires, mais plutôt à une approche différente de la modernité, où la référence à la "voie française », incontournable au début du $\mathrm{XX}^{\mathrm{e}}$ siècle, n'est plus de mise cinquante ans plus tard.

3 Le livre s'organise en quatre grandes parties qui portent sur l'ensemble des pays constituant ce que l'on appelle communément l'Amérique latine, du Mexique aux pays du Cône sud, et s'efforce de retracer les grandes étapes d'une histoire culturelle approchée dans le contexte des événements de l'époque. Ce parcours, très précisément tracé, nourri de très nombreuses statistiques, met bien en évidence la base très fragile des échanges entre la France et l'Amérique latine : faiblesse de l'émigration française, caractère très limité des échanges économiques, comparés notamment aux « concurrents » que sont l'Allemagne, l'Italie et surtout les Etats-Unis dont l'influence ira en se renforçant après la Première Guerre mondiale. Assez curieusement la place de la Grande-Bretagne est à peine évoquée alors que cette puissance joua pendant longtemps un rôle non négligeable dans la vie politique et économique de l'Amérique latine.

Denis Rolland montre bien ainsi que, très tôt, les liens qui unissent la France à l'Amérique latine se réduisent à des liens culturels qui ne concernent que les élites. La population dans son ensemble reste à l'écart de ces mouvements et sera certainement par la suite plus sensible à l'influence américaine et à l'anglais. Dès la fin de la Première Guerre les élites politiques et économiques commencent à se détourner de la France. Seules les élites artistiques et littéraires poursuivent la tradition du voyage à Paris. L'épisode de Vichy ne fera qu'affaiblir un peu plus l'image d'une France dont la culture ne fonctionne plus, au moins de façon déterminante, comme marqueur du rang social des élites.

5 La diffusion et l'enseignement du français en Amérique latine ne font pas l'objet d'un traitement spécifique, mais sont abordés au détour de différents chapitres. Un certain nombre de tableaux, précisément informés, donnent une idée assez claire de ce que pouvait être cet enseignement au début du siècle et ce qu'il est devenu dans les années 50. La place et le rôle de l'Alliance française y sont à différentes reprises évoqués.

6 L'ouvrage ouvre en même temps des perspectives de réflexion sur cet affaiblissement des représentations de la France, qui ne limite pas à la seule Amérique latine. Peut-être faudrait-il s'interroger sur cette relation à la modernité qui, à un certain moment, a donné à la France, à partir de l'héritage des Lumières et de celui de la Révolution, une image forte au travers d'un modèle universaliste et d'un modèle politique associé, celui de l'État-nation. Modernité qui, après la Seconde Guerre mondiale, passe par d'autres voies, notamment celle de la pensée économique, par l'élaboration de nouveaux modèles d'organisation et de régulation de la richesse des nations, dont la langue d'élaboration n'est pas le français. Domaines dans lesquels la France n'a apporté qu'une contribution limitée. Si Marianne thésaurise volontiers, elle n'a jamais en revanche prisé les marchands et leurs comptes, et ne s'est jamais piquée de culture économique.

7 Ouvrage dense, doté d'une abondante bibliographie, ainsi que d'un répertoire très détaillée des sources consultées. Un index organisé en noms de lieux et noms de personnes permet au lecteur d'évoluer plus aisément dans une matière 
particulièrement vaste. Ce travail d'historien ne manquera pas d'intéresser tous ceux qui souhaitent placer l'analyse des formes et pratiques de la diffusion et de l'enseignement du français en Amérique latine dans un contexte historique aux contours plus nettement tracés. 